Bond University

Research Repository

\title{
Environmental-specific servant leadership as a strategic tool to accomplish environmental performance: a case of China
}

Siddiquei, Ahmad; Asmi, Fahad; Asadullah, Muhammad Ali; Mir, Farhan

Published in:

International Journal of Manpower

DOI:

10.1108/IJM-07-2020-0350

Licence:

CC BY-NC

Link to output in Bond University research repository.

Recommended citation(APA):

Siddiquei, A., Asmi, F., Asadullah, M. A., \& Mir, F. (2021). Environmental-specific servant leadership as a strategic tool to accomplish environmental performance: a case of China. International Journal of Manpower, 42(7), 1161-1182. https://doi.org/10.1108/lJM-07-2020-0350

\section{General rights}

Copyright and moral rights for the publications made accessible in the public portal are retained by the authors and/or other copyright owners and it is a condition of accessing publications that users recognise and abide by the legal requirements associated with these rights.

For more information, or if you believe that this document breaches copyright, please contact the Bond University research repository coordinator. 


\title{
Title
}

Environmental-Specific Servant Leadership as a Strategic Tool to accomplish Environmental Performance: A Case of China

\begin{abstract}
Purpose: The Chinese firms are keenly focused on reducing their environmental footprints as part of the competitive strategy. Within the context of sustainable organizations in China, we test a multilevel framework that examined the impact of environmental-specific servant leadership on the green individual (pro-environmental behaviour) and team (project green performance) outcomes within projects. Using social identity theory, we theorize and test the mediating role of green self-identity (individual level) and team green identification (team level) in the relationships between environmental-specific servant leadership, pro-environmental behaviour, and project green performance.

Design/methodology/approach: We used survey questionnaires to collect multi-level and multi-wave data from 42 ongoing project-based sustainable organisations in China. The multilevel team to individual-level hypothesis were analysed using multilevel-modelling via Mplus, while team level hypotheses were tested using ordinary least squares regression.

Findings: The multilevel regression analysis showed that environmental-specific servant leadership has a trickle-down effect of green self-identity, which subsequently predicts pro-environmental behaviour. The ordinary least squares regression results demonstrated that environmental-specific servant leadership predicts project green performance via team green identification. Also, environmental-specific servant leadership has a positive and direct impact on pro-environmental behaviour and project green performance.
\end{abstract}

Originality: The study is among the first to understand the role of environmental-specific servant leadership in predicting individual and team level environment-related mediator and outcomes simultaneously.

Research limitations/implications: We offer community and service dimension of leadership as a determinant of environmental performance at multiple levels. We provide managerial and policy implications to Chinese organizations striving to re-position themselves as eco-friendly organizations both nationally and globally.

Keywords: Environmental-Specific Servant Leadership; green self-identity; team green-identification, pro-environment behaviour; project green performance; multi-level analysis; mainland China 


\section{Introduction}

In terms of system theory, every business holding a complex supply chain requires tangible and intangible resources as input to drive the output in the form of valuable product/service and by-product, i.e., ecological footprints. Minimizing environmental footprints is an essential part of corporate social responsibility for eco-smart organizations (Rajesh, 2020a). While aiming for a sustainable future, eco-conscious organizations strive to simultaneously balance social, ecological, and economic concerns (Reinhardt, Christodoulou, Gassó-Domingo, \& Amante García, 2019). Interestingly, institutional and regulatory forces have been considered significant and constructive to attain environmental objectives while emphasizing sustainable development (Yuan \& Zhang, 2020).

Among leading economies, China is accountable for the highest $\mathrm{CO}_{2}$ emission because of the rapidly growing renewable sector (Hurri, 2020). While addressing ecological concerns, the World has witnessed China's incredible journey from dead weight to the emerging global climate leader (Gao, 2018). Interestingly, in macro and macro-level implementation of green initiatives, organizational management's role could be a significant contributor to environmental management. Especially in China's case, one can see the noticeable gravity of governance emphasizing sustainability (D’Souza et al., 2020; M. Li, Dong, Luan, \& Wang, 2020).

Researchers have pointed out that leadership may influence their followers' green attitudes and behaviors through environmental policies and targets (Singh, Giudice, Chierici, \& Graziano, 2020). However, mere influence through a green strategy may not bear fruit without transforming such a plan into green work practices (Mi et al., 2019). Especially in China's context, we believe that environmental management requires organizational leaders to walk their talk by presenting themselves as ecological role models. In other words, we offer that the corporate leaders in China should display a more genuine and authentic concern towards environmental problems caused by 
the business operations. Unfortunately, the organizational and ecological literature has largely ignored the role of community-oriented or socially-responsible leadership dimensions in predicting green performance within the context of sustainable Chinese organizations. Existing studies have primarily focused on examining team or employee green performance and the intervening mechanisms to achieve such performance within Western economies and conventional organizational settings (e.g., Li et al., 2020; Luu, 2019; Singh et al., 2020). Authors believe that the current literature related to transition economies (China) emphasizes the role of institutions to define and regulate sustainable initiatives. The policymakers need smart integration of human resources to prepare the workforce towards sustainable culture and practices. Although the leadership can provide contextual leverage to subordinates in internalizing and exercising green work practices (Mi et al., 2019; Pham \& Kim, 2019), projects' functioning present substantial challenges to leaders. Therefore, such a context requires a different set of leadership competencies and skills to achieve performance compared to conventional work settings (Zhao, Hwang, \& Lim, 2020).

This study presents a multi-level framework that proposes the impact of environmentalspecific servant leadership on green performance (individual and team) via green self-identity and team green identification within a sustainable project context. According to Burns (1978) and Sendjaya and Cooper (2011), servant leadership encapsulates community-oriented leadership dimensions, which emphasizes ethics and moral values to elevate followers from their everyday selves to their better selves. While servant leaders are motivated to serve the community, Luu $(2018,2019)$ integrated servant leadership with the environment, labeled as EnvironmentalSpecific Servant Leadership (ESSL). ESSL focuses on helping the environment and exemplifying community stewardship and socially responsible behaviors (Afsar, Cheema, \& Javed, 2018; Luu, 2020). We consider that because of the sustainable and people-centric nature of projects, ESSL 
may play a crucial role in accomplishing project green performance at the team level and proenvironmental behavior at the individual-level simultaneously. Our theorization derives mainly from social identity theory (Ashforth \& Mael, 1989) that suggests that leaders can influence followers' actions only if they can modify their self-identity derived mainly from emotional attachment to and knowledge of group membership. Because ESSL leads with the motivation to serve and develop followers to accomplish environmental goals (Luu, 2018), team members are likely to identify themselves with the servant leader and consider him/her as an in-group member while working on projects. Consequently, team members would internalize and implement green and sustainable work strategies and behaviors during a project, consistent with their group norms (Ashforth \& Mael, 1989). Collectively, at the individual level, we propose that ESSL would shape follower's self-identity, conceptualized as green self-identity, and subsequent proenvironmental behaviors. At the team level, ESSL would influence team identification, conceptualized as team green identification, and consequent, project green performance.

Our study contributes to the literature on leadership and green management in three critical ways. Firstly, the framework may advise human resource-driven reforms to define, design, and implement sustainable practices as a part of green initiatives of business entities in China. The study may also facilitate the strategic re-positioning of China's business entities from economic to ecologically focused organizations. Secondly, we adopted a multi-level approach to assess ESSL's green outcomes at the individual and team level within the context of China regarded as a world leader in climate change practices. Further, we accounted for the multi-level mediators, green self-identity (individual level) and team green identification (team level), in the relationship between ESSL and green outcomes. Simultaneous inclusion of multi-level green leadership behavior, green individual and team identity-specific mediators, and green outcomes presents a unique and broad framework. A recent review by Eva, Robin, Sendjaya, van 
Dierendonck, and Liden (2019) has called for multi-level conceptualization and analysis of servant leadership in estimating its true effects on individual and team outcomes. Thus, our proposed model fulfills the literature gap by adopting a robust theoretical and methodological approach. Thirdly, our study contributes to ESSL's utility within the context of sustainable organizations, which is a new and emerging form of organizational structure (Ibrahim, Bartsch, \& Sharifi, 2020; Zhao et al., 2020). It is important to note that we explicitly focus on projects within sustainable and eco-friendly organizations in China. Scholars have pointed out that sustainability in projects and organizations demand eco-conscious and responsible leadership that aligns with environmental goals (Mazutis \& Abolina, 2019). Accordingly, our study examined the importance and effectiveness of ESSL within the project context and the trickledown effect of such leadership style in such a context.

2. Theory and Hypothesis

\subsection{Social identity theory and leadership}

A team member's sense of connectedness to a group and its subsequent influence on behavior has traditionally been viewed in terms of social identity (SI) theory (Tajfel \& Turner, 1985). Ashforth and Mael (1989) defined social identity as the "perception of oneness with or belongingness to some human aggregate' (p. 135). SI theory underpins three motivational processes: social categorization, social comparison, and social identification. Social categorization helps individuals make sense of their social environment by systematically organizing people surrounding them into different categories using social information processing (Ashforth \& Mael, 1989). Such categorization aids individuals emphasize shared characteristics of the group relevant to the current situation while neglecting variations (age, gender, background) that often exist among the same group members. It is important to note that meaning and significance attached to all categories are often "relational and comparative" (Tajfel \& 
Turner, 1985, p.16). Social comparison means individuals use social categories to judge different groups' status and worth; thereby, distinguishing between different groups based on their defining characteristics or behavioral norms (Ashforth \& Mael, 1989). Social identification is the process through which social information about various groups is related to the self. Identification enables individuals to consider himself/herself to be a representative of a particular group. Individuals realize their values (i.e., who they are as individuals?) and the group's values they perceive to be associated with (i.e., who they are as a unit?). Often, an individual's sense of self is derived from their group membership, leading them to adopt distinctive group norms as guidelines for their own behavior.

Team leadership is a social process of influencing followers (Oc \& Bashshur, 2013). There is a long history of examining the significance of social and personal identification in team leadership (Ibarra, Wittman, Petriglieri, \& Day, 2014; van Knippenberg, van Knippenberg, De Cremer, \& Hogg, 2005). From an ethical perspective, a team leader's critical challenge is to influence team members' moral identity so that each member's efforts could be directed towards responsible behaviors (Qin, Huang, Hu, Schminke, \& Ju, 2018). While self-identity is generally used to describe oneself (e.g., Cook, Kerr, \& Moore, 2002), it is usually driven by leader and group social interaction related to task demands and expectations at the workplace (Ellemers, De Gilder, \& Haslam, 2004; Whitmarsh \& O’Neill, 2010). Team members often use the team leader's interpersonal treatment as social information to make judgments about their status and value, driven mostly from their group identity (Chiniara \& Bentein, 2018). Using social comparison and social identification highlighted by SI theory (Ashforth \& Mael, 1989), we suggest that team leader's community-oriented and responsible behaviors develop a group's identity, which determines the values they adopt, the ethics and moral standards they maintain, and eventually, the way they behave responsibly as a distinct unit. 


\subsection{Leadership and sustainable organizations}

Corporate sustainable performance is a crucial research topic for managers and academics (Carter \& Washispack, 2018). Most of this research has identified the role of organizational leaders in accomplishing sustainable goals. In sustainable organizations, Rajesh (2020b) proposed the critical role of leadership decision-making in implementing sustainability checks at the strategic and operational levels. Leaders provide the enabling foundation for accomplishing environmental goals at the individual and team level (Rajesh, 2020b). Zhang, Pan, Jiang, and Feng (2020) suggested that managers should play an active role within and across organizations to manage their resources and supply chain and accomplish sustainable development strategies and environmental goals. A similar opinion shared by Laguir, Stekelorum, and El Baz (2020) suggesting that leaders must prioritize eco-friendly orientation in all business functions, including operation, warehousing, packaging, and supply chain management, to accomplish environmental performance. Using institutional theory, Rajesh and Rajendran (2019) showed that managers need to understand their environmental, social, and governance priorities and the extent to which each of them impacts the organization's sustainable performance. In Italian forestry firms, Toma, Miglietta, Morrone, and Porrini's (2020) concluded that organizational leaders could reduce environmental risk vulnerability by adopting corporate socially responsible actions. Pham and Kim (2019) showed that within the construction industry, leadership competencies such as vision, communication, empowerment, inspiration, and critical judgment moderates the relationship between corporate environmental practices and sustainability performance. They recommended that leaders inculcate ecological concern as a core element of their business and project strategy (Pham \& Kim, 2019). Jardon and Martínez-Cobas (2019) showed that leadership behavior has a far more significant role in accomplishing a sustainable advantage than organizational culture. While culture is essential to attain sustainable goals, but it must work through corporate leaders 
to achieve such goals. In a very recent study of sustainable manufacturing organizations, Eide, Saether, and Aspelund (2020) showed that leaders' intrinsic motivation for sustainable practices determines sustainable organizational strategy via intellectual leadership behavior related to sustainable environmental goals. They stated that "managers can do good, both for their firms and for the World, by following their own values and standards for sustainability. Such efforts speak to customers and other stakeholders through more meaningful product solutions, and by addressing key challenges in the firms' environments" (Eide et al., 2020; p. 9)

Consistent with previous literature, we argue that ESSL's social influence process is more significant within teams and project settings within sustainable organizations than conventional organizations (Jardon \& Martínez-Cobas, 2019; Lin \& Huang, 2010). Teams working within a project often perform the highly interdependent task. They need to ensure that they are accomplishing a task as well as green goals. The project context requires high-quality teamwork and coordination between team members (Bilal, Siddiquei, Asadullah, Awan, \& Asmi, 2020). The project leader's role is to ensure that every team member knows and understands its purpose, green values, and shared agenda to meet ecological goals. A lack of group identification with the green shared values and behavioral norms may result in the project's failure to meet environmental goals (Mesmer-Magnus, Asencio, Seely, \& DeChurch, 2018). Ineffective ESSL may not inspire followers to identify themselves as socially responsible employees, resulting in a lack of intent to accomplish green goals (Singh et al., 2020). Figure 1 shows our proposed theoretical model. In the next section, we expand these arguments to present our direct and indirect multi-level hypothesis. 


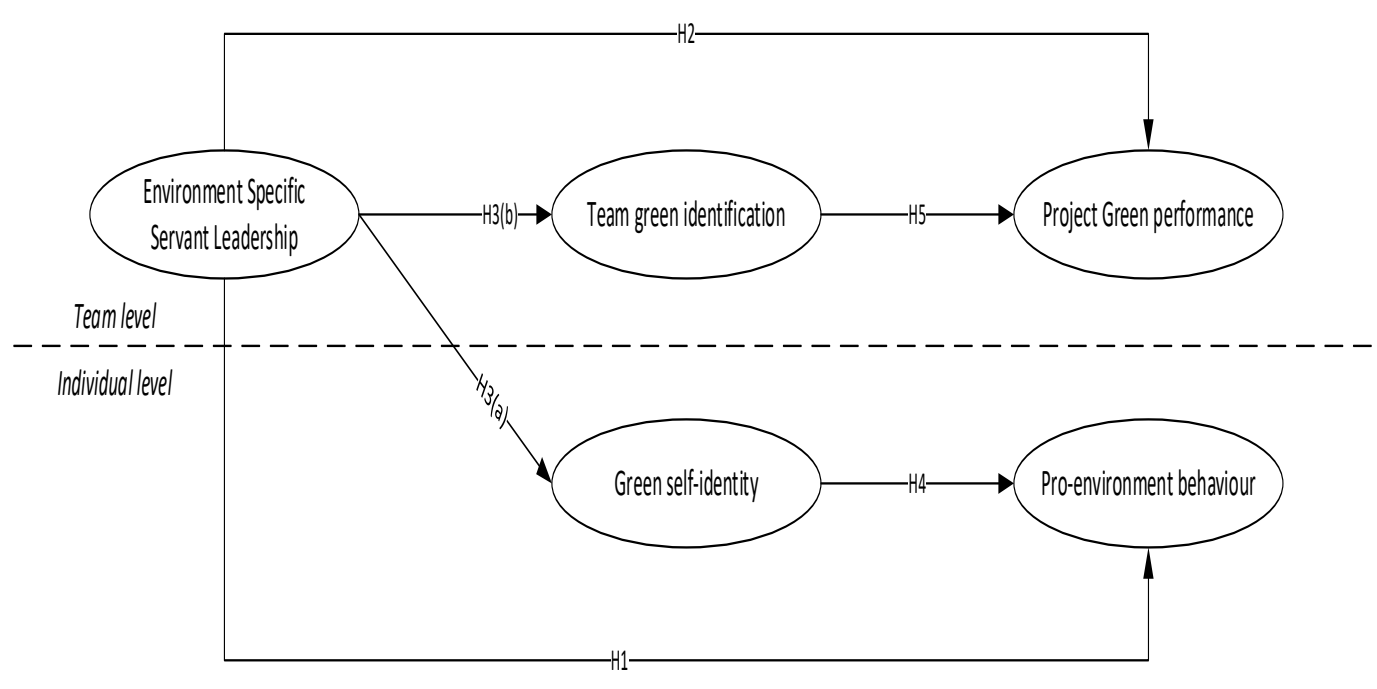

Figure 1: Proposed model

2.3. ESSL, pro-environmental behavior, and project green performances

At the individual level, Hale and Fields (2007) considered that servant leadership centers on social contribution and community welfare. Servant leadership de-emphasizes the leader's glorification. ESSL display altruistic and developmental values that are highly meaningful within sustainable organizations (Afsar et al., 2018). By observing ESSL, team members can also acquire similar service and community values in accomplishing their tasks as they engage in episodic future thinking (Hale \& Fields, 2007; van Dierendonck, 2011). Researchers have noted that servant leadership has a trickle-down effect on team members, inspiring followers to exercise community citizenship behaviors, and become servant leaders themselves (Ling, Lin, \& Wu, 2016). Because ESS leaders often serve as role models within organizations, project leader's ESSL would prepare their followers to develop and lead as environmental agents, indicated by pro-active environmental behavior (Afsar et al., 2018). Besides the environment, good servant leaders are focused on developing followers, and therefore, provide timely assistance while team members try to attain environmental goals and master new environmental-specific knowledge 
(Luu, 2020). Such leadership would build a creative resource pool among teams by instilling community orientation and encouraging green learning (Luu, 2019; Yoshida, Sendjaya, Hirst, \& Cooper, 2014). Servant leaders also provide task and personal resources and encourage and support followers to build resources such as knowledge, skills, and autonomy, which fuel their competence and motivation in the production of creative environmental solutions (Ruiz-Palomino \& Zoghbi-Manrique-de-Lara, 2020).

At the team level, ESSL can be viewed as a leadership practice that places environmental benefits over economic benefits for himself or herself and the organization, focusing on the cultivation of pro-environmental values in organizational stakeholders. Luu (2018) suggests extending servant leadership's focus on the environmental target and examining the role of such an ecological form of servant leadership in shaping targeted eco-friendly outcomes. Considering Greenleaf (1977) and van Dierendonck (2011) perspective of servant leadership, ESSL believes that business organizations should assume social responsibility as one of the primary objectives. The board of directors should take primary responsibility for evaluating and facilitating progress on this objective. Within the conventional organizational settings like tourism and hospitality, there is some evidence ESSL facilities accomplishing green performance (e.g., Luu, 2020). Thus, we expected ESSL's altruistic and environmental orientation to aid accomplishment at the individual level environmental behavior and team-level environmentally-friendly goals. H1: Team ESSL would positively and significantly impact pro-environmental behavior at the individual level.

H2: Team ESSL would positively and significantly impact project green performance at the team level. 


\subsection{ESSL and green identity}

We propose that ESSL would foster green self-identity and team green identification.

Following SI theory, self-identity refers to the self-concept subgroup that involves selfidentification (Tajfel \& Turner, 1985). Gardner and Avolio (1998) define self-identification as the process of showing the self to be a particular type of person or, more formally as "fixing and expressing one's own identity privately through reflection about oneself and publicly through self-disclosures, self-presentations and other activities" (p. 33). According to SI theory, followers develop their identity, such as green self-identity and team green identification, based on their social and work-related interactions with the team leader (Ellemers et al., 2004). Within organizations, such identity reflects the extent to which subordinates identify themselves as environment-friendly entities both as individuals and groups.

Servant leaders generate great acceptance and awareness among followers at two levels: individual and team level (Chen, Zhu, \& Zhou, 2015). Servant leadership involves showing respect and consideration toward team members, and thus, likely to be perceived as in-group members by the teams. ESS leaders focus on building their long-term sustainable work practices and competencies (Luu, 2019). The team's experiencing high ESSL observe and understand responsible and sustainable leadership values and goals. Consequently, such principles are internalized to develop their green identity both at the individual and the team level. Besides displaying sustainable leadership practices, ESSL "catalyze the resource caravan to instill green value into employees" (Luu, 2019, p. 92). Such leadership would inspire followers to internalize green and socially responsible work practices, making them a core element of their self-identity. Followers would be more engaged in understanding and adopting the green values and exhibiting them in performing routine job duties. 
Two of the key characteristics of servant leadership include nurturing and empowering team members, letting subordinates determine the best course of action to serve their needs (van Dierendonck, 2011). In this aspect, ESSL would encourage team members to take green initiatives at the personal and collective level vis-à-vis bringing responsible solutions to the project problems. ESSL would empower followers to take significant steps during a project for the well-being of society and environment, and subsequently, developing their green identities. Such follower and community-centric leadership approach would also facilitate a sense of responsibility within teams to build and nurture their green identities. Another critical characteristic of ESSL is their ability to listen to team members, learn about their needs and aspirations related to project environmental goals, and share their pain and frustration when the project cannot accomplish such goals (Mark A. Rennaker, 2008). By focusing on team members' individual needs, ESSL would build trust by being completely honest and open about environmental protection efforts and policies. This would reinforce belief in followers, facilitating them to identify and maintain themselves as green and responsible members of society. Team members of the ESS leader are likely to show more helping and citizenship work behaviors rather than working as individuals with self-serving goals (Chiniara \& Bentein, 2018). Team members experience a greater sense of environmental responsibility when they understand that their leader's strategy includes environment protection, pro-environmental, recycling, and energy efficiency mechanisms. Employees identify strongly with their leaders when they genuinely believe that society's collective interests supersede personal goals. Compatibility between their own and leader's values is higher (Newman, Schwarz, Cooper, \& Sendjaya, 2017). Suppose a servant leader can influence followers to become moral agents. In that case, the result may be an environmental-oriented culture that encourages and supports sustainable green goals. 
H3: Team ESSL would positively and significantly impact team member's identity at the individual and team level, including (a) green self-identity and (b) team green identification.

2.5. Green identity, pro-active environmental behavior, and project green performance We propose that green self-identity and team green identification would be positively related to individual-level pro-environment behaviors and team level project green performance. Self-identity serves to differentiate oneself from others and conform to the values, beliefs, and actions of the social groups to which one belongs (Ashforth \& Mael, 1989). Previous research within psychology and leadership showed that individuals with strong efficacy beliefs tend to accept challenges, handle difficult and unconventional tasks, and accomplish high task goals (Judge, Jackson, Shaw, Scott, \& Rich, 2007). Indeed, project context presents an environment where tasks are complex, challenging, and unfamiliar, requiring team members to believe in their capabilities and work with a robust collective purpose. Often, team members with a strong sense of identity display community-oriented behaviors beyond the call of duty (Payne \& Webber, 2006). Besides, team members with high group identification work beyond formal job requirements and take initiatives when necessary to accomplish collective goals (Judge et al., 2007). Likewise, it is essential to note that the project context is interdependent, requiring proactive and pro-social behaviors by team members to accomplish collective goals. Project team members distinguishing themselves on their green identity are likely to work together, share an emotional bond, and bring creative environmental solutions during a project. Therefore, we expect that the communal orientation underlying team members' green identity should motivate them to take better care of the environment individually and collectively (i.e., pro-active environmental behaviors and project green performance). In other words, strong personal and 
team green identification motivates project team members not only to accomplish sustainable personal goals but also to be more creative and proactive in accomplish team level green goals. H4: Green self-identity would positively impact pro-environmental behavior at the individual level.

H5: Team green identification would positively impact project green performance at the team level.

Integrating the previous direct effect hypothesis suggests that green self-identity and the team's green-identification would mediate the relationships between ESSL, pro-active environmental behaviors, and project green performance. Rather than using positional power inculcated to leadership's role to influence team members, ESSL relies on personal moral capabilities to develop responsible behaviors within followers (Sousa \& van Dierendonck, 2017). ESSL saw the seed of community well-being through their moral values, encouraging team members to align their values with the leader's values. Previous research has shown that efficacy beliefs and group identification mediate the relationships between servant leadership and extrarole and discretionary workplace behaviors (Chen et al., 2015).

H6: Green self-identity mediates the relationship between team ESSL and pro-active environmental behavior at the individual level.

H7: Team green identification mediates the relationship between team ESSL and project green performance at the team level.

3. Method

3.1. Context, participants, and procedure

We conducted this survey in the provinces of Anhui and Zhejiang from mainland China. We focused on Hangzhou, Hefei, Wenzhou Yiwu, and Ningbo, which holds a distinctive economic contribution to the country. The authors approached a couple of trade exhibition 
promoters to obtain the commercial players' contact and accessibility that serve the domestic or international market. However, the authors' preference was not considered while enlisting related organizations. Thus, the study could claim to adopt random sampling for the data collection. As the eligibility criteria to define the surveyed sample, we initially inquired the representatives of each potential organization about (1) the use of Solar Photovoltaics (PV) technology in the organization, (2) the emphasizes on ecological concerns as a part of the corporate social responsibility and as a core organizational value, and (3) project-based nature of the work (i.e., the strict timeline to be followed). A positive response to all three questions qualified the organization as a potential study participant. The adopted strategy allowed us to cover diverse industrial sectors, i.e., information technology, construction, and power industry, to generalize mainland China's current findings.

The data was collected in two-waves to reduce potential common method bias, which often arises from cross-sectional research design (Podsakoff, MacKenzie, Lee, \& Podsakoff, 2003). In the first wave (Time 1), we administered surveys from project team members who rated their 'leader's ESSL, green self-identity, team green identification, and pro-environmental behavior. At Time 1, member's also provided information about their demographic background. In the second wave (Time 2), conducted at least three weeks after Time 1, we asked project managers to rate their team's green performance in the project (s). Project managers also provided information on their demographic background (i.e., gender education, experience) and team size. Because team members were nested within projects, a unique identification code was printed on each questionnaire to match the team member survey. To classify as an eligible candidate, the authors contacted 137 organizations. However, only 83 on-going project-based organizations satisfied the criteria stated above. On the formal invitation to be part of the current study, only 45 organizational teams participated in the study, making a response rate of $54.22 \%$. We kept only 
those project teams in our sample whom we received responses from both team leaders and at least 2 team members. 42 teams had 125 team members fit this criterion and retained in the final analysis.

The demographic composition of team members included female (56\%) and male (44\%). Approximately $42 \%$ of members worked in the industry for 1 to 5 years, $32 \%$ had 5 to 10 years of experience, and $25 \%$ had greater than 10 years of industry experience. $45 \%$ of members held a bachelor's degree, $44 \%$ held a master's qualification, and $11 \%$ of respondents had a technical diploma. In terms of gender and education, approximately $49 \%$ of females had a bachelor's degree, $40 \%$ had a master's degree, and $11 \%$ held a technical diploma. $40 \%$ of males had a bachelor's degree, $49 \%$ had a master's degree, and $11 \%$ had a technical certification. In terms of gender and experience, approximately $37 \%$ of females worked in the industry for 1 to 5 years, while $31 \%$ of females each had a work experience of either 5 to 10 years or greater than 10 years. Approximately $49 \%$ of males had worked in the industry for 1 to 5 years, $33 \%$ had work experience between 5 to 10 years, and the remaining $18 \%$ had greater than 10 years of industry experience. The average team size was 3.08, with a minimum of 2 and a maximum of 5 team members (excluding the leader).

\subsection{Measures}

Project team members were asked to rate their current project leader's ESSL, green selfidentity, and team green identification. Project leader's rated project team green performance. Except noted otherwise, we used a five-point Likert scale of $1=$ "strongly disagree" to $5=$ "strongly agree." 


\subsubsection{Independent variable}

A 16-item scale that Luu (2018) adapted from Liden, Wayne, Zhao, \& Henderson (2008) was used to assess ESSL. The scale has previously used by Afsar et al. (2018) and demonstrated acceptable reliability. Two sample items include: "My project manager emphasizes the importance of contributing to the environmental improvement" and "I am encouraged by my manager to volunteer in the environmental activities."

\subsubsection{Mediating variables (individual and team level)}

Green self-identity was assessed, adapting 4-items scale from Whitemarsh and O'Neil (2010). A sample item includes: "I think of myself as an environmentally-friendly employee." Team green identification was measured using a 4-items scale from Lee (2009). The scale explicitly reflected green identity in a social context, which resonates with the team-based context of this study. One sample item includes: "I often discuss environmental issues with my team members."

\subsubsection{Dependent variables (individual and team level)}

The pro-environmental behavior scale developed by Robertson and Barling (2013) was used for this study. Sample items include: "At work, I take part in environmentally friendly programs." Team green performance was measured using 8-items developed by Chen, Lai, and Wen (2006), reflecting the extent to which the project accomplishes sustainability and environmental goals in performing project functions. Two sample item includes: "the green innovation project chooses the materials of the product that consume the least amount of energy and resources for conducting the product development or design" and "the operation process developed by the green innovation project effectively reduces the emission of hazardous substances or waste." 


\subsubsection{Control variables}

Besides primary variables, we included four control variables including, gender, education $($ Bachelors $=1$, Masters $=2$, and Diploma $=3)$, experience $(1-5$ years $=1,5-10$ years $=$ 2, and greater than 10 years $=3$ ), and team size (rated by leaders).

\subsection{Analytical strategy}

We performed the analysis in two-steps. In the first step, we verified the reliability and validity of the variables. Also, we ran a series of Confirmatory Factor Analysis (CFA) to establish the empirical distinguishes of independent and mediating constructs measured at the individual level of analysis. In the second step, we tested the hypothesis using Multi-Level Modeling (MLM) and Ordinary Least Squares (OLS) regression. The conceptualization and measurement of variables were performed at two different analysis levels, as participating individuals are team members and leaders nested within project teams. MLM is particularly wellsuited for analyzing hierarchically nested data structures where micro-level observations (individuals) are nested within units (groups/teams) (Bliese, 2000; Hofmann, 1997; Raudenbush \& Bryk, 2002). MLM's primary advantage allows researchers to simultaneously investigate relationships within, between, and across different hierarchical levels (González-Romá \& Hernández, 2017; Hofmann, 1997; Hofmann \& Gavin, 1998). We estimated the cross-level effect of ESSL on green self-identity and pro-environmental behavior using MLM (Hypothesis 1, 3a, 4, and 6). At the same time, we tested relationships between ESSL, team green identification, and project green performance at the team level using OLS $(2,3 b, 5$, and 7$)$.

4. Results

\subsection{Reliability and Validity of Constructs}

The measurement model was assessed to ensure reliability, convergent validity, and discriminant validity. The reliability was evaluated using Cronbach's $\alpha$, composite reliability 
Table 1: Reliability and convergent validity

\begin{tabular}{|c|c|c|c|c|c|}
\hline & Indicator & Loadings & Cronbach's Alpha & $\mathrm{CR}$ & AVE \\
\hline \multirow[t]{16}{*}{ ESSL } & ESSL1 & 0.75 & 0.97 & 0.97 & 0.69 \\
\hline & ESSL2 & 0.80 & & & \\
\hline & ESSL3 & 0.81 & & & \\
\hline & ESSL4 & 0.78 & & & \\
\hline & ESSL5 & 0.78 & & & \\
\hline & ESSL6 & 0.81 & & & \\
\hline & ESSL7 & 0.86 & & & \\
\hline & ESSL8 & 0.92 & & & \\
\hline & ESSL9 & 0.63 & & & \\
\hline & ESSL10 & 0.69 & & & \\
\hline & ESSL11 & 0.92 & & & \\
\hline & ESSL12 & 0.91 & & & \\
\hline & ESSL13 & 0.95 & & & \\
\hline & ESSL14 & 0.75 & & & \\
\hline & ESSL15 & 0.96 & & & \\
\hline & ESSL16 & 0.87 & & & \\
\hline \multirow{4}{*}{ Green self-identity (GSI) } & GSI1 & 0.89 & 0.91 & 0.91 & 0.72 \\
\hline & GSI2 & 0.76 & & & \\
\hline & GSI3 & 0.88 & & & \\
\hline & GSI4 & 0.86 & & & \\
\hline \multirow[t]{5}{*}{ Green team identification } & GTI1 & 0.96 & 0.95 & 0.95 & 0.78 \\
\hline & GTI2 & 0.92 & & & \\
\hline & GTI3 & 0.84 & & & \\
\hline & GTI4 & 0.77 & & & \\
\hline & GTI5 & 0.92 & & & \\
\hline \multirow{11}{*}{ Pro-environmental behavior (PEB) } & PEB1 & 0.85 & 0.97 & 0.97 & 0.72 \\
\hline & PEB2 & 0.90 & & & \\
\hline & PEB3 & 0.66 & & & \\
\hline & PEB4 & 0.83 & & & \\
\hline & PEB5 & 0.69 & & & \\
\hline & PEB6 & 0.83 & & & \\
\hline & PEB7 & 0.91 & & & \\
\hline & PEB8 & 0.91 & & & \\
\hline & PEB9 & 0.90 & & & \\
\hline & PEB10 & 0.93 & & & \\
\hline & PEB11 & 0.88 & & & \\
\hline \multirow[t]{9}{*}{ Project green performance (PGP) } & PGP1 & 0.90 & 0.97 & 0.97 & 0.76 \\
\hline & PGP2 & 0.93 & & & \\
\hline & PGP3 & 0.77 & & & \\
\hline & $\begin{array}{l}\text { PGP4 } \\
\text { to }\end{array}$ & 0.80 & & & \\
\hline & PGP5 & 0.82 & & & \\
\hline & PGP6 & 0.78 & & & \\
\hline & PGP7 & 0.86 & & & \\
\hline & PGP8 & 0.97 & & & \\
\hline & PGP9 & 0.96 & & & \\
\hline
\end{tabular}

(CR), and average variance extracted (AVE). As shown in Table 1, the Cronbach's $\alpha$ and CR of each construct were higher than the recommended value of 0.70 , and the AVEs of all the constructs were above 0.60 . Hence, all constructs demonstrated acceptable reliability. The convergent and discriminant validities were further examined for construct validity. The standard 
loadings of all items were higher than the desired threshold of 0.60 and significant at 0.01 , which indicated a good convergent validity (Table 1).

The discriminant validity was assessed via Fornell and Larcker criterion and heterotraitmonotrait ratio of correlations (HTMT) (Henseler, Hubona, \& Ray, 2016). The results appear in Appendix A. The Fornell and Larcker criterion showed that the square roots of the AVEs (the bold numbers in the diagonal) were greater than the correlation between constructs (Fornell \& Larcker, 1981), while the values of HTMT ratio were below the acceptable threshold of 0.90 (Henseler et al., 2016). Overall, the results provide sufficient evidence of discriminant validity.

\subsection{Measurement model using Confirmatory Factor Analysis (CFA)}

In the next step, we ran a series of CFA. We compared the fitness of three different theoretical parsimonious models that explains how well the measured variables represent the number of constructs hypothesized to occur in a model. The CFA results are presented in Table 2. The proposed three-factor model, ESSL, green self-identity, and team green identification, showed better fit to the data by demonstrating fit indices well-above the cut-off criteria: $\left(\chi^{2}=\right.$ 353.69$, d.f. $=186, \mathrm{CFI}=.93, \mathrm{TLI}=.92, \mathrm{IFI}=.93$, and $\mathrm{RMSEA}=.08)^{1}$. In the alternative twofactor model, we loaded items measuring green self-identity and green team-identification on a single latent factor, while ESS on a different factor. The model did not show adequate fit to the data with the fitness values below the acceptable range $\left(\chi^{2}=554.01\right.$, d.f. $=188, \mathrm{CFI}=.85, \mathrm{TLI}=$ .84 , IFI $=.85$, and RMSEA $=.12$ ). Lastly, we ran a CFA on by loading all items measuring ESSL, green self-identity, and team green identification on a single latent factor and found unsatisfactory results $\left(\chi^{2}=902.18, d . f .=189, \mathrm{CFI}=.72, \mathrm{TLI}=.69, \mathrm{IFI}=.72\right.$, and $\mathrm{RMSEA}=$ .17). Thus, we retained the three-factor model for hypothesis testing.

\footnotetext{
${ }^{1}$ To refine our scales, we deleted three items measuring ESSL and one item measuring team green identification based on squared multiple correlation.
} 
Table 2: Confirmatory factor analysis at the individual level

\begin{tabular}{|c|c|c|c|c|c|c|c|}
\hline Models & Description & $\chi^{2}$ & d.f. & CFI & TLI & IFI & RMSEA \\
\hline Model 1 & $\begin{array}{l}\text { One-Factor: ESSL, green self-identity, and team green } \\
\text { identification loaded on one latent construct }\end{array}$ & 902.18 & 189 & .72 & .69 & .72 & .17 \\
\hline Model 2 & $\begin{array}{l}\text { Two-Factor: ESSL (one latent construct) and green self- } \\
\text { identity and team green identification (one latent construct) }\end{array}$ & 554.01 & 188 & .85 & .84 & .85 & .12 \\
\hline Model 3 & $\begin{array}{l}\text { Three-Factor: ESSL, green self-identity, and team green } \\
\text { identification loaded on three separate latent constructs }\end{array}$ & 353.69 & 186 & .93 & .92 & .93 & .08 \\
\hline
\end{tabular}

Notes. ESSL $=$ Environmental-specific servant leadership

\subsection{Data Aggregation}

Because of the multi-level data nature, we tested whether team member scores could justifiably be aggregated to team level scores (Bliese, 2000). We used two different but complementary inter-class correlation (ICC) statistics to justify aggregation, including ICC (1) and ICC (2). The ICC (1) values for ESSL and team green identification was .56 and .67, respectively, while ICC (2) values for ESSL and team green identification was .79 and .86, respectively. These results suggest that aggregation is justified (LeBreton \& Senter, 2008).

\subsection{Model testing}

Table 3 presents the descriptive statistics and correlations between variables at the individual level of analysis. We use MLM to examine the top-down direct and indirect effects of ESSL on green self-identity and pro-environmental behavior (see Table 4), while we use OLS to estimate the team level direct influence of ESSL on project green performance and indirectly via team green identification (see Table 5). Since we were interested in examining the direct and mediation effects, we followed the multistep approach proposed by Baron and Kenny (1986). To support the mediation hypothesis, Baron and Kenny (1986) suggested three conditions: a) independent variable must predict the dependent variable, $b$ ) independent variable must predict 
the mediating variable, and c) mediating variable must predict the dependent variable controlling for the independent variable. Further, we report the bootstrapped confidence intervals for the indirect mediation hypothesis.

Table 3: Descriptive statistics and correlations between study variables at the individual level

\begin{tabular}{|c|c|c|c|c|c|c|c|c|c|c|}
\hline Constructs & $\mathrm{M}$ & SD & 1 & 2 & 3 & 4 & 5 & 6 & 7 & 8 \\
\hline Gender & 1.44 & .49 & & & & & & & & \\
\hline Experience & 1.83 & .81 & -.15 & & & & & & & \\
\hline Education & 1.66 & .67 & .06 & -.01 & & & & & & \\
\hline Team size & 3.08 & .59 & .04 & .02 & -.09 & & & & & \\
\hline ESSL & 3.53 & .90 & .00 & $-.22 *$ & .02 & $-.31 * *$ & . & & & \\
\hline Green self-identity & 4.27 & .85 & .04 & $-.20 *$ & -.02 & $-.49 * *$ & $.55 * *$ & & & \\
\hline Team green identification & 4.18 & 1.08 & .07 & -.14 & -.04 & $-.57 * *$ & $.55^{* *}$ & $.59 * *$ & & \\
\hline Pro-environmental behavior & 4.12 & .91 & .06 & -.13 & -.02 & $-.57 * *$ & $.56^{* *}$ & $.74 * *$ & $.69 * *$ & \\
\hline Project green performance & 3.53 & 1.01 & -.07 & -.09 & .06 & $-.60 * *$ & $.58 * *$ & $.51 * *$ & $.73^{* *}$ & $.58 * *$ \\
\hline
\end{tabular}

Notes. $\mathrm{N}=125$ team members, 42 teams, ${ }^{* *} p<0.01,{ }^{*} p<0.05$, Cronbach's alpha values are presented on the diagonal, a: $1=$ Female, $2=$ Male, $\mathrm{b}$ : $1=1-5$ years, $2=5-10$ years, $3=10-15$ years, $4=>15$ years, c: $1=$ Bachelors, $2=$ Masters, $3=$ Diploma, ESSL $=$ Environmental-specific servant leadership, $\mathrm{M}=$ Mean, S.D. $=$ Standard deviation

In terms of Hypothesis 1 and 2, team ESSL is significantly related to team member's proenvironmental behavior $(\gamma=.71, p<.01)$, as shown in Model 1 Table 3, and to project team performance $(\beta=.65, p<.01)$, as presented in Model 1 Table 4. Hypothesis 1 and 2 are supported. Hypothesis $3 \mathrm{a}$ and $3 \mathrm{~b}$ predicted that team ESSL would be positively and significantly related to green self-identity (individual level) and team green identification (team level). The results of MLM and OLS showed that ESSL is positively and significantly associated with green self-identity $(\gamma=.55, p<.01)$ and team green identification $(\beta=.60, p<.01)$, as shown in Model 2 Table 4 and Model 2 Table 5, respectively. Hypothesis 4 suggested that green self-identity predicts pro-environmental behavior at the individual level. As presented in Model 3 Table 4, the results of MLM supported the hypothesis $(\gamma=.71, p<.01)$. At the team level, Hypothesis 5 predicted that team green identification would be associated with project green performance. The results of OLS supported this assertion $(\beta=.72, p<.01)$, as shown in Model 3 Table 5. 
Table 4: Results of multi-level modeling (Model 2-1-1) predicting relationships between ESSL, green self-identity, and pro-environmental behavior

\begin{tabular}{|c|c|c|c|c|}
\hline & $\begin{array}{c}\text { Model } 1 \\
\text { Pro-environmental behavior }\end{array}$ & $\begin{array}{c}\text { Model } 2 \\
\text { Green self-identity }\end{array}$ & $\begin{array}{c}\text { Model } 3 \\
\text { Pro-environmental behavior }\end{array}$ & $\begin{array}{c}\text { Model } 4 \\
\text { Pro-environmental behavior }\end{array}$ \\
\hline Intercepts & $3.42(1.981-4.716)$ & $\begin{array}{c}4.05 * *(2.184- \\
5.487)\end{array}$ & $.93 * *(.127-1.766)$ & $2.44 * *(1.174-3.797)$ \\
\hline \multicolumn{5}{|l|}{ Level 1} \\
\hline Gender & $.07(-.155-.292)$ & $.08(-.226-.332)$ & $.01(-.197-.253)$ & $.02(-.134-.195)$ \\
\hline Experience & $-.05(-.223-.073)$ & $-.10(-.333-.059)$ & $-.00(-.0171-.175)$ & $-.02(-.133-.079)$ \\
\hline Education & $-.104(-.278-.064)$ & $-.14(-.360-.071)$ & $-.00(-.132-.170)$ & $-.08(-.214-.065)$ \\
\hline Green self-identity & & & $.71 * * *(.572-.849)$ & $.29 * *(.184-.393)$ \\
\hline \multicolumn{5}{|l|}{ Level 2} \\
\hline Team size & $-.53 * *(-.808--.254)$ & $\begin{array}{c}-.41 * *(-.707-- \\
.085)\end{array}$ & & $-.47 * *(-.686--.197)$ \\
\hline ESSL & $.71 * *(.491-.942)$ & $.55 * *(.308-.826)$ & & $.55 * *(.328-.847)$ \\
\hline
\end{tabular}

leadership

Regarding cross-level mediation (Hypothesis 6), we regressed pro-environmental behavior on ESSL and green self-identity in the same equation. As shown in Model 4 Table 4, both $\operatorname{ESSL}(\gamma=.55, p<.01)$ and green self-identity $(\gamma=.29, p<.01)$ are positively related to proenvironmental behavior. Satisfying the third condition of Baron and Kenny (1986), the results showed that green self-identity mediates the relationship between ESSL and pro-environmental behavior, lending support to Hypothesis 6. Finally, to test the team level mediating role of team green identification, we entered ESSL and team green identification simultaneously to predict project green performance. As presented in Model 4 Table 5, both ESSL $(\beta=.36, p<.05)$ and green team identification $(\beta=.45, p<.01)$ positively predicts project green performance. Thus, the third mediation condition suggested by Baron and Kenny (1986) was upheld, supporting Hypothesis 7. Moreover, to confirm the mediation hypothesis, we examined the product of 
coefficients Cis, which verified the significant indirect effects of team ESSL on pro-

environmental behavior through green self-identity $(\mathrm{CI} 95 \%=[.09, .24])$, and the bootstrapped significant indirect effects of team ESSL on project green performance through team green identification $(\mathrm{CI} 95 \%=[0.02,0.74])$. Taken together, mediation Hypothesis 6 and 7 are further supported.

Table 5: Results of hierarchical linear regression predicting relationships between ESSL, green team identification, and project green performances

\begin{tabular}{lcccc}
\hline & $\begin{array}{c}\text { Model 1 } \\
\text { Project green } \\
\text { performance }\end{array}$ & $\begin{array}{c}\text { Model } 2 \\
\text { Green team identification }\end{array}$ & $\begin{array}{c}\text { Model 3 } \\
\text { Project green } \\
\text { performance }\end{array}$ & $\begin{array}{c}\text { Model } 4 \\
\text { Project green } \\
\text { performance }\end{array}$ \\
\hline Constant & $1.87(1.17)$ & $3.67^{* *}(1.13)$ & $.64(1.26)$ & $.06(1.19)$ \\
Team experience & $.07(.22)$ & $.01(.21)$ & $-.01(.20)$ & $.07(.20)$ \\
Team education & $.01(.19)$ & $-.12(.19)$ & $.10(19)$ & $.07(.18)$ \\
Team size & $-.30^{*}(.19)$ & $-.35^{* *}(.18)$ & $-.09(.20)$ & $-.13(.19)$ \\
ESSL & $.65^{* *}(.15)$ & & & $.36^{*}(.17)$ \\
$\mathrm{R}^{2}$ & & $.60^{* *}(.14)$ & $.72 * *(.12)$ & $.47^{* *}(.15)$ \\
\end{tabular}

Notes. $\mathrm{N}=42$ teams (aggregated scores), ${ }^{* *} p<0.01,{ }^{*} p<0.05$, Values in parentheses are standard errors, standard coefficients are report, $\mathrm{R}^{2}=$ Squared multiple correlation, ESSL $=$ Environmental-specific servant leadership

\section{Discussion}

The role of leadership has been regarded as pivotal to influence followers' green attitudes and behaviors (Ibrahim et al., 2020). In this study, we examined a multi-level framework that examined the trickle-down effect of the project leader's ESSL on sustainable and green behaviors both at the individual and team level. Our results showed that ESSL directly impacts proenvironmental behavior at the individual level and projects sustainable performance at the team level. At the individual level, ESSL shapes green self-identity, which subsequently nurtures proenvironmental behaviors. At the team level, ESSL develops team green identification and facilitates the accomplishment of sustainable project goals. 


\subsection{Theoretical implications}

The study provides useful findings that contribute to mainstream leadership and green management literature. First, we found that ESSL brings more visibility to the project's sustainable performance by fueling team members' green identities as they internalized the environment-friendly behavior of their leader (Chen, Zhu, \& Zhou, 2015). This study showed that ESSL is highly significant within organizations that prioritize the environment as part of their business strategy. ESSL eradicates the group boundaries (feeling of out-group) by reducing the differentiation over the pro-environmental element in leadership (Newman et al., 2017). Consistent with SI theory, reciprocating the green elements as in-group would foster the green identity at individual level and encourage sustainable concerns of the project. Environmentally sensitive leaders can affect their team members' behavior through sustainable identity by enhancing their understanding of green and sustainable work practices. This is in line with previous research that has shown the trickle-down ethical and moral effect of servant leaders on followers' pro-social behaviors (e.g., Ling et al., 2016).

Second, sustainable organizations are striving for a win-win solution regarding China, whereby they can strike a balance between ecological and economic concerns. The ESSL within eco-friendly and sustainable organizations may provoke a positive behavioral change by emphasizing sustainable practices. In this regard, ESSL attempts to balance the economic and social orientation of a business entity. On the one hand, ESSL helps followers internalize and identify themselves as green individuals by presenting themselves as eco-responsible role models. This will help the organization to accomplish green project goals. On the other, servant leaders place followers first. Such leadership tends to provide necessary job resources to followers to engage in creative green initiatives (Luu, 2019). Such an approach to leadership would help to accomplish the economic goals of the organization. 


\subsection{ESSL vs. conventional leadership}

From a strategic perspective, today's organizations strive to be in the blue-ocean to benefit from being unique, distinctive, differentiated, and competitive. Apart from supporting or adapting Porter or Mintzberg's view and gaining a competitive position, the greener view is increasingly getting the essential value in business strategy. However, at the present moment, the adaption and internalizing the greener view is still a key challenge for most business entities (Mi et al., 2019). In a recent study, Ren, Tang, and Jackson (2020) noted that "In an era when governments and consumers recognize that business activities can and do cause lasting environmental damage, business leaders are being pressured to accept more responsibility for protecting and even renewing the Earth's finite and depleted natural resources" ( $p$. ahead of print). Global business organizations are devising innovative strategies to reduce their operations' environmental footprints (Rajesh, 2020a). In line with these arguments, ESSL shapes individual and team level behaviors and facilitates environmentally responsible business operations. Such leadership provides a strategic advantage to organizations beyond traditional leadership approaches. When leaders are engaged in ethical and socially responsible leadership, the organizational strategies strongly impact the commitment to accomplish environmental goals (Ren et al., 2020).

\subsection{Managerial implications}

From a managerial perspective, the current study suggests three practical implications for Chinese organizations and their adaptation to sustainable policies. Firstly, organizations must strive to build ESSL among their project managers through training and development programs and succession planning policies. The project manager serves as a role model to a tightly knitted project team. By placing followers first and displaying green values, project managers are in an 
ideal spot to develop and nurture a green self-concept within team members. Second, while mapping sustainable governance for project managers over the Deming cycle (Plan-Do-CheckAct (PDCA)), we may conclude that Act may help managers to develop sustainable competencies through learning new skills and tools during a project lifecycle (Cardoni, Kiseleva, \& Lombardi, 2020). Adapting the generalized view of Act by Cardoni, Kiseleva, and Lombardi (2020), we underline the critical role via leader-driven sustainable Act while developing and practicing green competency in sustainable organizations. Thus, we suggest that project managers have a neverending responsibility and pro-active role in incentivizing green work practices among team members. This recognition will encourage team members to make sustainable decisions in their routine project tasks. Our recommendation corresponds with the argument of Todaro, Testa, Daddi, and Iraldo (2019), who emphasized the role of a leader (as organizational support) while mapping the individual's cognitive factors (during internalizing green value). Mainly, ESSL's effect can be concluded as the essential determinant of any sustainable organization's socially responsible initiatives in the future.

Third, at a national level, China has remained a point of environmental debate for its widespread business activities (Hurri, 2020). As a world's factory, China has been remarkably revolutionized in technology adaption due to its strong absorptive capacity (Wu, Wang, Hong, Piperopoulos, \& Zhuo, 2016). However, the strategic shift from traditional business competitiveness to green and sustainable entities is the requirement of time. Therefore, we suggest that: (1) Chinese firms attract eco-concerned project managers to be part of the sustainable organizations by computing individuals' eco-literacy, green self-efficacy, and greenidentity of recruitment criteria and (2) managers in Chinese organizations should focus on green role-modeling by adapting servant leader practices so that the greener image of Chinese society and business entities could be improved nationally and globally. 


\subsection{Limitations and future research}

The study's findings should be interpreted considering the following limitations, which paves the way for future research. First, participants reported their perceived pro-environmental behaviors, which may be biased by social-desirability. Although Gifford and Nilsson (2014) note that self-reported green behaviors and objective measurement of such behavior are correlational, nevertheless, we note this as a potential limitation of this study. Future research might measure green behaviors through the objective instrument and examine the magnitude of the difference between subjective and objective measurement. Second, we measured all independent and dependent variables using a cross-sectional approach. Thus, we cannot confidently conclude the causal relationship between ESSL and green identity at the individual and team level.

Accordingly, future research could design a longitudinal study to measure ESSL and green identity at different project stages. This will allow the researcher to positively conclude that ESSL causes green identity and subsequently helps to accomplish green objectives. Third, we did not account for moderators and boundary conditions in our theoretical model. Future research could focus on when ESSL is most influential in accomplishing green goals within project settings. One possible moderator could green organizational identity, defined as an "interpretive scheme about environmental management and protection that members collectively construct in order to provide meaning to their behaviors" (Chen, 2011, p. 388). Third, although we used strict criteria and random sampling to approach green organization within our study, all participating organizations belonged to China. The same model should be replicated in Western countries so that cultural factors may be observed in the proposed relationships (Ahmad, Fazal-e-Hasan, \& Kaleem, 2020). 


\subsection{Conclusion}

Environmental management is a growing problem for business organizations across the World. The organizational workforce requires to authentically think, understand, and deliberate about ecological footprints' intensity because of business operations. Leadership is critical to ensure that followers consider this problem seriously and develop eco-friendly behaviors at the individual and collective levels. This study showed that ESSL may positively facilitate accomplishing environmental goals by nurturing green values and identity in project team members. To achieve green goals, leaders need to be more authentic in recognizing ecological problems and lead by example to effectively communicate and transform their green values and identities to their teams. ESSL working within sustainable projects provide a strategic advantage to their organizations. Such leaders will often nurture green team values and place environmental goals as an integral part of project goals.

\section{References}

Afsar, B., Cheema, S., \& Javed, F. (2018). Activating employee's pro-environmental behaviors: The role of CSR, organizational identification, and environmentally specific servant leadership. Corporate Social Responsibility and Environmental Management, 25(5), 904-911. https://doi.org/10.1002/csr.1506

Ahmad, S., Fazal-e-hasan, S., \& Kaleem, A. (2020). Is the meaning of ethical leadership constant across cultures? A test of cross-cultural measurement invariance. International Journal of Manpower, ahead-of-print(ahead-ofprint). https://doi.org/10.1108/IJM-02-2019-0079

Ashforth, B. E., \& Mael, F. (1989). Social Identity Theory and the Organization. Academy of Management Review, 14(1), 20-39. https://doi.org/10.5465/amr.1989.4278999

Bilal, A., Siddiquei, A., Asadullah, M., Awan, H., \& Asmi, F. (2020). Servant leadership: a new perspective to explore project leadership and team effectiveness. International Journal of Organizational Analysis (2005), ahead-of-print(ahead-of-print). https://doi.org/10.1108/IJOA-12-2019-1975

Bliese, P. D. (2000). Within-group agreement, non-independence, and reliability: Implications for data aggregation and analysis. In Katherine J. Klein \& Steve W. J. Kozlowski (Eds.), Multi-level theory, research, and methods in organizations: Foundations, extensions, and new directions (1st ed., pp. 349-381). https://doi.org/TBD

Burns, J. (1978). Leadership (1st ed.). New York: Harper \& Row.

Cardoni, A., Kiseleva, E., \& Lombardi, R. (2020). A sustainable governance model to prevent corporate corruption: Integrating anticorruption practices, corporate strategy and business processes. Business Strategy and the Environment, (August 2019), 1-13. https://doi.org/10.1002/bse.2424

Carter, C., \& Washispack, S. (2018). Mapping the Path Forward for Sustainable Supply Chain Management: A Review of Reviews. Journal of Business Logistics, 39(4), 242-247. https://doi.org/10.1111/jbl.12196

Chen, Y. S., Lai, S. B., \& Wen, C. T. (2006). The influence of green innovation performance on corporate advantage in Taiwan. Journal of Business Ethics, 67(4), 331-339. https://doi.org/10.1007/s10551-006-9025-5

Chen, Z., Zhu, J., \& Zhou, M. (2015). How does a servant leader fuel the service fire? A multi-level model of servant leadership, individual self identity, group competition climate, and customer service performance. Journal of

This is a post-peer-review, pre-copyedit version of an article published in International Journal of Manpower. The final authenticated version is available online at: https://doi.org/10.1108/IJM-07-2020-0350

This author accepted manuscript is deposited under a Creative Commons Attribution Non-commercial 4.0 International (CC BY-NC) licence. This means that anyone may distribute, adapt, and build upon the work for non-commercial purposes, subject to full attribution. If you wish to use this manuscript for commercial purposes, please contact permissions@emerald.com. 
Applied Psychology, 100(2), 511-521. https://doi.org/10.1037/a0038036

Chiniara, M., \& Bentein, K. (2018). The servant leadership advantage: When perceiving low differentiation in leader-member relationship quality influences team cohesion, team task performance and service OCB. Leadership Quarterly, 29(2), 333-345. https://doi.org/10.1016/j.leaqua.2017.05.002

Cook, A. J., Kerr, G. N., \& Moore, K. (2002). Attitudes and intentions towards purchasing GM food. Journal of Economic Psychology, 23(5), 557-572. https://doi.org/10.1016/S0167-4870(02)00117-4

D’Souza, C., McCormack, S., Taghian, M., Chu, M. T., Sullivan Mort, G., \& Ahmed, T. (2020). An empirical examination of sustainability for multinational firms in China: Implications for cleaner production. Journal of Cleaner Production, 242, 118446. https://doi.org/10.1016/j.jclepro.2019.118446

Eide, A., Saether, E., \& Aspelund, A. (2020). An investigation of leaders' motivation, intellectual leadership, and sustainability strategy in relation to Norwegian manufacturers' performance. Journal of Cleaner Production, 254, 120053-. https://doi.org/10.1016/j.jclepro.2020.120053

Ellemers, N., De Gilder, D., \& Haslam, S. A. (2004). Motivating Individuals and Groups at Work: A Social Identity Perspective on Leadership and Group Performance. The Academy of Management Review, 29(3), 459. https://doi.org/10.2307/20159054

Eva, N., Robin, M., Sendjaya, S., van Dierendonck, D., \& Liden, R. C. (2019). Servant Leadership: A systematic review and call for future research. Leadership Quarterly, 30(1), 111-132. https://doi.org/10.1016/j.leaqua.2018.07.004

Fornell, C., \& Larcker, D. (1981). Structural Equation Models with Unobservable Variables and Measurement Error: Algebra and Statistics. Journal of Marketing Research, 18(3), 382-. https://doi.org/10.2307/3150980

Gao, X. (2018). China's evolving image in international climate negotiation: From copenhagen to paris. China Quarterly of International Strategic Studies, 4(2), 213-239. https://doi.org/10.1142/S2377740018500112

Gardner, W., \& Avolio, B. (1998). The Charismatic Relationship: A Dramaturgical Perspective. The Academy of Management Review, 23(1), 32-58. https://doi.org/10.2307/259098

Gifford, R., \& Nilsson, A. (2014). Personal and social factors that influence pro-environmental concern and behaviour: A review. International Journal of Psychology, Vol. 49, pp. 141-157. https://doi.org/10.1002/ijop.12034

González-Romá, V., \& Hernández, A. (2017). Multi-level Modeling: Research-Based Lessons for Substantive Researchers. Annual Review of Organizational Psychology and Organizational Behavior, 4(1), 183-210. https://doi.org/10.1146/annurev-orgpsych-041015-062407

Greenleaf, R. K. (1977). Servant Leadership: A Journey Into the Nature of Legitimate Power and Greatness. New York: Paulist Press.

Hale, J. R., \& Fields, D. L. (2007). Exploring servant leadership across cultures: A study of followers in Ghana and the USA. Leadership, 3(4), 397-417. https://doi.org/10.1177/1742715007082964

Henseler, J., Hubona, G., \& Ray, P. (2016). Using PLS path modeling in new technology research: updated guidelines. Industrial Management + Data Systems, 116(1), 2-20. https://doi.org/10.1108/imds-09-2015-0382

Hofmann, D. A. (1997). An Overview of the Logic and Rationale of Hierarchical Linear Models. Journal of Management, 23(6), 723-744. https://doi.org/10.1177/014920639702300602

Hofmann, D. A., \& Gavin, M. B. (1998). Centering Decisions in Hierarchical Linear Models: Implications for Research in Organizations. Journal of Management, 24(5), 623-641. https://doi.org/10.1177/014920639802400504

Hurri, K. (2020). Rethinking climate leadership: Annex I countries' expectations for China's leadership role in the post-Paris UN climate negotiations. Environmental Development, 100544. https://doi.org/10.1016/j.envdev.2020.100544

Ibarra, H., Wittman, S., Petriglieri, G., \& Day, D. V. (2014). Leadership and Identity: An Examination of Three Theories and New Research Directions. In David V. Day (Ed.), The Oxford Handbook of Leadership and Organizations (pp. 285-301). https://doi.org/10.1093/OXFORDHB/9780199755615.013.015

Ibrahim, A., Bartsch, K., \& Sharifi, E. (2020). Green infrastructure needs green governance: Lessons from Australia's largest integrated stormwater management project, the River Torrens Linear Park. Journal of Cleaner Production, 261, 121202. https://doi.org/10.1016/j.jclepro.2020.121202

Jardon, \& Martínez-Cobas. (2019). Leadership and Organizational Culture in the Sustainability of Subsistence Small Businesses: an Intellectual Capital Based View. Sustainability (Basel, Switzerland), 11(12), 3491-. https://doi.org/10.3390/su11123491

Judge, T. A., Jackson, C. L., Shaw, J. C., Scott, B. A., \& Rich, B. L. (2007). Self-efficacy and work-related performance: The integral role of individual differences. Journal of Applied Psychology, 92(1), 107-127. https://doi.org/10.1037/0021-9010.92.1.107 
Laguir, I., Stekelorum, R., \& El Baz, J. (2020). Going green? Investigating the relationships between proactive environmental strategy, GSCM practices and performances of third-party logistics providers (TPLs). Production Planning \& Control, 1-14. https://doi.org/10.1080/09537287.2020.1784483

LeBreton, J. M., \& Senter, J. L. (2008). Answers to 20 Questions About Interrater Reliability and Interrater Agreement. Organizational Research Methods, 11(4), 815-852. https://doi.org/10.1177/1094428106296642

Lee, K. (2009). Gender differences in Hong Kong adolescent consumers' green purchasing behavior. Journal of Consumer Marketing, 26(2), 87-96. https://doi.org/10.1108/07363760910940456

Li, M., Dong, L., Luan, J., \& Wang, P. (2020). Do environmental regulations affect investors? Evidence from China's action plan for air pollution prevention. Journal of Cleaner Production, 244. https://doi.org/10.1016/j.jclepro.2019.118817

Li, W., Bhutto, T. A., Xuhui, W., Maitlo, Q., Zafar, A. U., \& Ahmed Bhutto, N. (2020). Unlocking employees' green creativity: The effects of green transformational leadership, green intrinsic, and extrinsic motivation. Journal of Cleaner Production, 255, 120229. https://doi.org/10.1016/j.jclepro.2020.120229

Liden, R. C., Wayne, S. J., Zhao, H., \& Henderson, D. (2008). Servant leadership: Development of a multidimensional measure and multi-level assessment. Leadership Quarterly, 19(2), 161-177. https://doi.org/10.1016/j.leaqua.2008.01.006

Lin, T. C., \& Huang, C. C. (2010). Withholding effort in knowledge contribution: The role of social exchange and social cognitive on project teams. Information and Management, 47(3), 188-196. https://doi.org/10.1016/j.im.2010.02.001

Ling, Q., Lin, M., \& Wu, X. (2016). The trickle-down effect of servant leadership on frontline employee service behaviors and performance: A multi-level study of Chinese hotels. Tourism Management, 52, 341-368. https://doi.org/10.1016/j.tourman.2015.07.008

Luu, T. T. (2018). Activating tourists' citizenship behavior for the environment: the roles of CSR and frontline employees' citizenship behavior for the environment. Journal of Sustainable Tourism, 26(7), 1178-1203. https://doi.org/10.1080/09669582.2017.1330337

Luu, T. T. (2019). Building employees' organizational citizenship behavior for the environment: The role of environmentally-specific servant leadership and a moderated mediation mechanism. International Journal of Contemporary Hospitality Management, 31(1), 406-426. https://doi.org/10.1108/IJCHM-07-2017-0425

Luu, T. T. (2020). Environmentally-specific servant leadership and green creativity among tourism employees: dual mediation paths. Journal of Sustainable Tourism, 28(1), 86-109. https://doi.org/10.1080/09669582.2019.1675674

Mark A. Rennaker. (2008). Listening and persuasion: Examining the communicative patterns of servant leadership (Regent University). Retrieved from https://pqdtopen.proquest.com/doc/193733342.html?FMT=ABS

Mazutis, D., \& Abolina, E. (2019). The Five I Model of Sustainability Leadership: Lessons from the Zibi One Planet Living sustainable urban development. Journal of Cleaner Production, 237, 117799. https://doi.org/10.1016/j.jclepro.2019.117799

Mesmer-Magnus, J. R., Asencio, R., Seely, P. W., \& DeChurch, L. A. (2018). How Organizational Identity Affects Team Functioning: The Identity Instrumentality Hypothesis. Journal of Management, 44(4), 1530-1550. https://doi.org/10.1177/0149206315614370

Mi, L., Gan, X., Xu, T., Long, R., Qiao, L., \& Zhu, H. (2019). A new perspective to promote organizational citizenship behaviour for the environment: The role of transformational leadership. Journal of Cleaner Production, 239, 118002. https://doi.org/10.1016/j.jclepro.2019.118002

Newman, A., Schwarz, G., Cooper, B., \& Sendjaya, S. (2017). How Servant Leadership Influences Organizational Citizenship Behavior: The Roles of LMX, Empowerment, and Proactive Personality. Journal of Business Ethics, 145(1), 49-62. https://doi.org/10.1007/s10551-015-2827-6

Oc, B., \& Bashshur, M. R. (2013, December 1). Followership, leadership and social influence. Leadership Quarterly, Vol. 24, pp. 919-934. https://doi.org/10.1016/j.leaqua.2013.10.006

Payne, S. C., \& Webber, S. S. (2006). Effects of service provider attitudes and employment status on citizenship behaviors and customers' attitudes and loyalty behavior. Journal of Applied Psychology, 91(2), 365-378. https://doi.org/10.1037/0021-9010.91.2.365

Pham, H., \& Kim, S. Y. (2019). The effects of sustainable practices and managers' leadership competences on sustainability performance of construction firms. Sustainable Production and Consumption, 20, 1-14. https://doi.org/10.1016/j.spc.2019.05.003

Podsakoff, P. M., MacKenzie, S. B., Lee, J. Y., \& Podsakoff, N. P. (2003, October). Common Method Biases in Behavioral Research: A Critical Review of the Literature and Recommended Remedies. Journal of Applied Psychology, Vol. 88, pp. 879-903. https://doi.org/10.1037/0021-9010.88.5.879 
Qin, X., Huang, M., Hu, Q., Schminke, M., \& Ju, D. (2018). Ethical leadership, but toward whom? How moral identity congruence shapes the ethical treatment of employees. Human Relations, 71(8), 1120-1149. https://doi.org/10.1177/0018726717734905

Rajesh, R. (2020a). Exploring the sustainability performances of firms using environmental, social, and governance scores. Journal of Cleaner Production, 247, 119600. https://doi.org/10.1016/j.jclepro.2019.119600

Rajesh, R. (2020b). Sustainable supply chains in the Indian context: An integrative decision-making model. Technology in Society, 61, 101230-. https://doi.org/10.1016/j.techsoc.2020.101230

Raudenbush, S. W., \& Bryk, A. S. (2002). Hierarchical Linear Models (2nd ed.). Retrieved from https://au.sagepub.com/en-gb/oce/hierarchical-linear-models/book9230

Rajesh, R., \& Rajendran, C. (2019). Relating Environmental, Social, and Governance scores and sustainability performances of firms: An empirical analysis. Business Strategy and the Environment, 29(3), 1247-1267. https://doi.org/10.1002/bse.2429

Reinhardt, R., Christodoulou, I., Gassó-Domingo, S., \& Amante García, B. (2019). Towards sustainable business models for electric vehicle battery second use: A critical review. Journal of Environmental Management, 245(May), 432-446. https://doi.org/10.1016/j.jenvman.2019.05.095

Ren, S., Tang, G., \& Jackson, S. (2020). Effects of Green HRM and CEO ethical leadership on organizations' environmental performance. International Journal of Manpower, ahead-of-print(ahead-of-print). https://doi.org/10.1108/IJM-09-2019-0414

Robertson, J. L., \& Barling, J. (2013). Greening organizations through leaders' influence on employees' proenvironmental behaviors. Journal of Organizational Behavior, 34(2), 176-194. https://doi.org/10.1002/job.1820

Ruiz-Palomino, P., \& Zoghbi-Manrique-de-Lara, P. (2020). How and when servant leaders fuel creativity: The role of servant attitude and intrinsic motivation. International Journal of Hospitality Management, 89. https://doi.org/10.1016/j.ijhm.2020.102537

Sen, S., \& Cooper, B. (2011). Servant Leadership Behaviour Scale: A hierarchical model and test of construct validity. European Journal of Work and Organizational Psychology, 20(3), 416-436. https://doi.org/10.1080/13594321003590549

Singh, S. K., Giudice, M. Del, Chierici, R., \& Graziano, D. (2020). Green innovation and environmental performance: The role of green transformational leadership and green human resource management. Technological Forecasting and Social Change, 150, 119762. https://doi.org/10.1016/j.techfore.2019.119762

Sousa, M., \& van Dierendonck, D. (2017). Servant Leadership and the Effect of the Interaction Between Humility, Action, and Hierarchical Power on Follower Engagement. Journal of Business Ethics, 141(1), 13-25. https://doi.org/10.1007/s10551-015-2725-y

Tajfel, H., \& Turner, J. C. (1985). The Social Identity Theory of Intergroup Behavior. In S. Worchel \& William G. Austin (Eds.), Psychology of intergroup relations (2nd ed., pp. 7-24). Chicago: Nelson-Hall.

Todaro, N. M., Testa, F., Daddi, T., \& Iraldo, F. (2019). Antecedents of environmental management system internalization: Assessing managerial interpretations and cognitive framings of sustainability issues. Journal of Environmental Management, 247(June), 804-815. https://doi.org/10.1016/j.jenvman.2019.06.106

Toma, P., Miglietta, P., Morrone, D., \& Porrini, D. (2020). Environmental risks and efficiency performances: The vulnerability of Italian forestry firms. Corporate Social-Responsibility and Environmental Management. https://doi.org/10.1002/csr.2002

van Dierendonck, D. (2011, July). Servant leadership: A review and synthesis. Journal of Management, Vol. 37, pp. 1228-1261. https://doi.org/10.1177/0149206310380462

van Knippenberg, B., van Knippenberg, D., De Cremer, D., \& Hogg, M. A. (2005, August 1). Research in leadership, self, and identity: A sample of the present and a glimpse of the future. Leadership Quarterly, Vol. 16, pp. 495-499. https://doi.org/10.1016/j.leaqua.2005.06.006

Whitmarsh, L., \& O'Neill, S. (2010). Green identity, green living? The role of pro-environmental self-identity in determining consistency across diverse pro-environmental behaviours. Journal of Environmental Psychology, 30(3), 305-314. https://doi.org/10.1016/j.jenvp.2010.01.003

Wu, J., Wang, C., Hong, J., Piperopoulos, P., \& Zhuo, S. (2016). Internationalization and innovation performance of emerging market enterprises: The role of host-country institutional development. Journal of World Business, 51(2), 251-263. https://doi.org/10.1016/j.jwb.2015.09.002

Yuan, B., \& Zhang, Y. (2020). Flexible environmental policy, technological innovation and sustainable development of China's industry: The moderating effect of environment regulatory enforcement. Journal of Cleaner Production, 243, 118543. https://doi.org/10.1016/j.jclepro.2019.118543

Zhang, Q., Pan, J., Jiang, Y., \& Feng, T. (2019). The impact of green supplier integration on firm performance: The 
mediating role of social capital accumulation. Journal of Purchasing and Supply Management, 26(2), 100579-. https://doi.org/10.1016/j.pursup.2019.100579

Zhao, X., Hwang, B. G., \& Lim, J. (2020). Job Satisfaction of Project Managers in Green Construction Projects: Constituents, Barriers, and Improvement Strategies. Journal of Cleaner Production, 246.

https://doi.org/10.1016/j.jclepro.2019.118968

This is a post-peer-review, pre-copyedit version of an article published in International Journal of Manpower. The final authenticated version is available online at: https://doi.org/10.1108/IJM-07-2020-0350

This author accepted manuscript is deposited under a Creative Commons Attribution Non-commercial 4.0 International (CC BY-NC) licence. This means that anyone may distribute, adapt, and build upon the work for non-commercial purposes, subject to full attribution. If you wish to use this manuscript for commercial purposes, please contact permissions@emerald.com. 


\section{Appendix A}

\begin{tabular}{lccccc}
\hline Constructs & ESSL & GSI & GTI & PEB & PGP \\
\hline ESSL & $\mathbf{0 . 8 3}$ & & & & \\
Green self-identity (GSI) & 0.35 & $\mathbf{0 . 8 5}$ & & & \\
Green team identification (GTI) & 0.31 & 0.39 & $\mathbf{0 . 8 8}$ & & \\
Pro-environmental behavior (PEB) & 0.33 & 0.63 & 0.50 & $\mathbf{0 . 8 5}$ & \\
Project green performance (PGP) & 0.37 & 0.31 & 0.58 & 0.38 & $\mathbf{0 . 8 7}$ \\
\hline
\end{tabular}

Fornell and Larcker method for Discriminant Validity

Squared correlations; AVE's square root in the diagonal

HTMT Discriminant validity

\begin{tabular}{lllll}
\hline \multicolumn{1}{c}{ Constructs } & ESSL & GSI & GTI & PEB \\
\hline ESSL & & & & \\
Green self-identity (GSI) & 0.59 & & & \\
Green team identification (GTI) & 0.55 & 0.63 & & \\
Pro-environmental behavior (PEB) & 0.58 & 0.79 & 0.71 & 0.76 \\
Project green performance (PGP) & 0.60 & 0.56 & 0.61 \\
\hline
\end{tabular}

